\title{
A Receipt and Credit Note from Sixth-Century Hermopolis
}

\author{
Nikolaos Gonis*
}

\begin{abstract}
Revised edition of a fragmentary text concerning for the reimbursement of one solidus to an oil-worker, issued by Zacharias, vir clarissimus.
\end{abstract}

Keywords: Zacharias, vir clarissimus; oil-worker; $\kappa \tau \hat{\mu} \alpha$ 'I $\mathrm{\lambda}$ íov

DOI 10.1515/apf-2016-0010

Some thirty years ago, L.S.B. MacCoull, published fifty-seven mostly fragmentary papyri acquired in Egypt by $\mathrm{H}$. Hyvernat, and housed at the Institute of Christian Oriental Research, Catholic University of America. ${ }^{1}$ The great majority of the papyri are Coptic, but there are also a few Greek. The latter category includes no. 19 (inv. 75.02), edited on p. 56 and reproduced in pl. I. Study of the plate and of digital images has resulted in the revised edition offered below (the points of divergence from $e d . p r$. are too numerous to be worth recording).

The text is the left part of a receipt and credit note issued by Zacharias, vir clarissimus, to Apollos, oil-worker. Apollos had earlier paid one solidus minus six carats for a reason that is no longer known, and Zacharias credits him with this amount; the subscription seems to imply that the solidus was paid to Apollos directly.

The format (cf. P.Jena II, p. 104 with n. 280) and wording point to Hermopolis as the provenance. This same Zacharias must be the one who issued BGU XIX 2792, a papyrus found at Hermopolis and assigned to the

Vorbemerkung: I am grateful to Chrysi Kotsifou for answering my first enquiries on this papyrus back in 2003, and to Monica Blanchard for imaging the papyrus on two occasions (2003 and 2015). My thanks are also due to Jean Gascou for reading a draft.

* Kontakt: Nikolaos Gonis, Department of Greek and Latin, University College London, London WC1E 6BT, United Kingdom, <n.gonis@ucl.ac.uk>

\footnotetext{
1 'Coptic Documentary Papyri in the Hyvernat Collection', BSAC 27 (1985) 53-60.
} 
sixth century. The hand of the present text and the rate of deduction of the carats suggest a date in the second half of the sixth century.

1

$\pi(\alpha \rho \grave{)}) Z \alpha \chi \alpha \rho i ́ o v ~ \lambda[\alpha \mu \pi \rho o(\tau \alpha ́ \tau o v)$

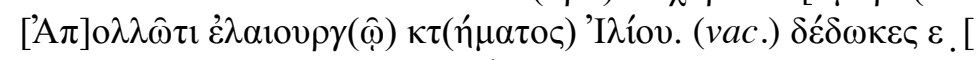

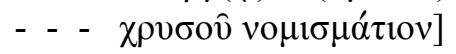

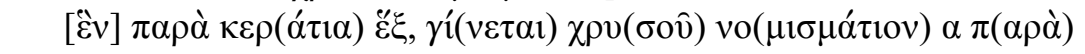

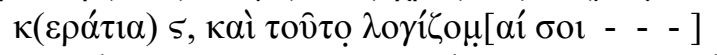

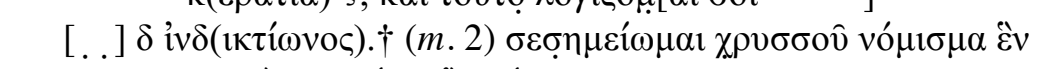

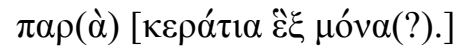

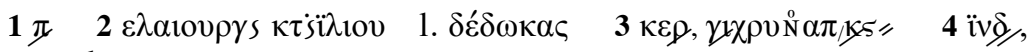
$\pi \alpha \rho$ 1. $\chi \rho v \sigma o \hat{v}$

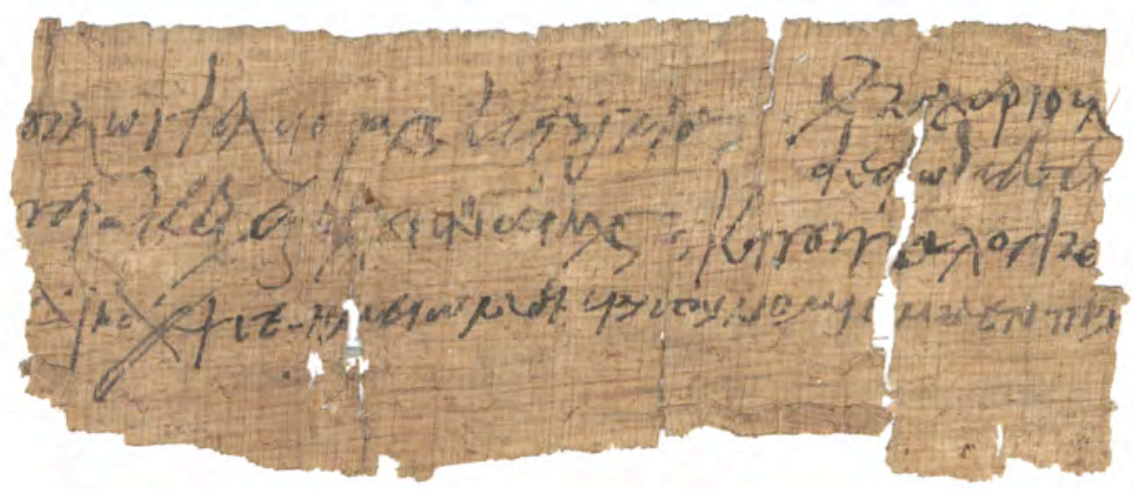

'From Zacharias, vir clarissimus, to Apollos, oil-maker of the holding of Iliou. You have given ... one gold solidus minus six carats, total 1 gold solidus minus 6 carats, and I credit this to you ... indiction 4.' ( $2^{\text {nd }}$ hand) ' $I$ have countersigned one gold solidus minus six carats only(?).'

1-2 For the arrangement of the prescript cf. e.g. BGU XII 2195.1f. (VI)

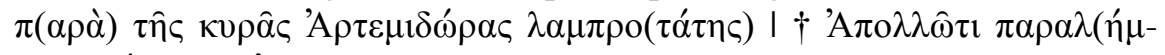

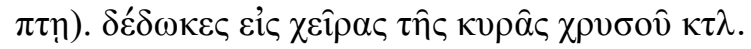




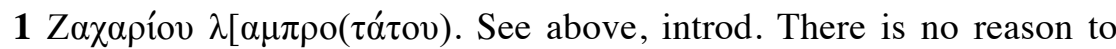
identify this person with Zacharias who issued the orders P.Vind. Tand. 30 and SPP III 309.

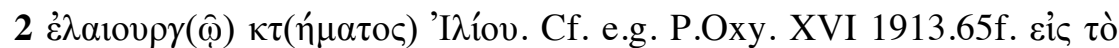

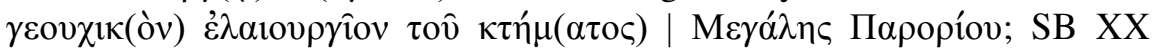

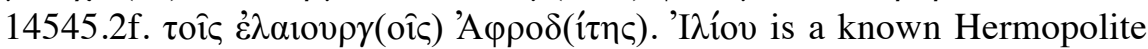

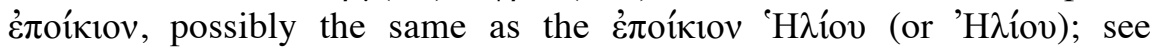
M. Drew-Bear, Le nome hermopolite (1979) 133 and 106 respectively. This suggests reading $\kappa \tau$ ń $\mu \alpha \tau o \varsigma$ rather than $\kappa \tau$ ń $\sigma \varepsilon \omega \varsigma$; on the issue see P.Sorb. II 69, pp. 38-42. However, the terms could have been used interchangeably with settlements; contrast SPP VIII $1034.2 \kappa \tau \eta \dot{n} \mu(\alpha \tau \circ \varsigma) \Theta \alpha \lambda$ -

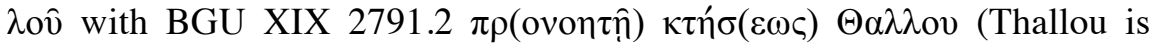
known as a $\kappa \omega ́ \mu \eta)$.

$\varepsilon .[: \varepsilon v[$ or $\varepsilon \pi[;$ not $\varepsilon i ̣[\zeta$.

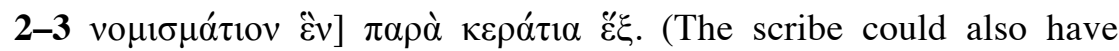
written vó $\mu 1 \sigma \mu \alpha$ : cf the subscription in 1. 4.) Solidi of the 'minus 6 carats' variety are attested in Hermopolis between 533 (SB XXIV 16284) and 604 (P.Bodl. 41); cf. also K. Maresch, Nomisma und Nomismatia (1994) 162-169.

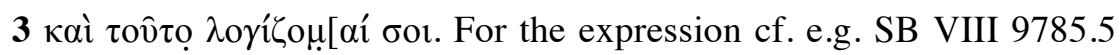
(VI; V/VI ed.pr.). It is common in Hermopolite receipts (see BGU XII $2184.4 \mathrm{n}$.), as well as in others from further south; see J. Gascou, TMByz 16 (2010) 368f. (7-8 n.), with references.

The second (putative) omicron of $\tau$ ov̂ $\tau$ ọ contains an extra stroke as if alpha were intended. 